\title{
ISRADIPINE - A CALCIUM CHANNEL BLOCKER - DOES NOT POTENTIATE CHLOROQUINE ANTIPLASMODIAL ACTIVITY AGAINST PlasmodIUM falCIPARUM
}

\author{
RANDRIANARIVELOJOSIA M.**** \& JAMBOU R. *****
}

\section{Summary:}

Culturing fresh clinical isolates of $P$. falciparum and using the isotopic method, we tested separately chloroquine and isradipine - a calcium channel blocker -, and also the combination isradipine plus chloroquine. Tested wild isolates were chloroquinesensitive. With regard to the combination isradipine/chloroquine, the isobolograms obtained indicate that isradipine antagonises chloroquine antiplasmodial activity. Taking into account these findings, we discuss the issues related to the calcium channel blocker molecules.

KEY WORDS : chloroquine, isradipine, Plasmodium falciparum, Madagascar.
Résumé : L'ISRADIPINE - UN INHIBITEUR DE CANAUX CALCIQUES NE POTENTIALISE PAS L'ACTIVITÉ ANTIPLASMODIALE DE LA CHLOROQUINE SUR PLASMODIUM FALCIPARUM

Des isolats de P. falciparum fraîchement prélevés de malades ont été testés pour évaluer leurs réponses in vitro à la chloroquine, à l'isradipine (un inhibiteur de canaux calciques), et à la combinaison isradipine/chloroquine. Les tests de chimiosensibilité ont été réalisés avec la méthode isotopique. Ces isolats sauvages étaient sensibles à la chloroquine. Quant à la combinaison isradipine/chloroquine, les isobologrammes obtenus indiquent un antagonisme entre les deux molécules. Tenant compte de ces résultats, nous soulevons dans cet article l'importance de la compréhension du métabolisme calcique des parasites du paludisme; et l'énigme de la réversion de la chloroquinorésistance par certaines molécules inhibitrices des canaux calciques.

MOTS CLÉS : chloroquine, isradipine, Plasmodium falciparum, Madagascar.<smiles>COC(=O)C1=C(C)NC(C)=C(C(=O)OC(C)C)C1c1cccc2nonc12</smiles>

Fig. 1. - Chemical structure of isradipine.

\section{MATERIAL AND METHODS}

IN VITRO PLASMODIUM FALCIPARUM CHEMOSENSITIVITY TESTS

\footnotetext{
linical $P$. falciparum isolates were collected from consenting patients in Saharevo. Samples were transported to the Malaria Research Unit at the "Institut Pasteur de Madagascar" where the isotopic in vitro chemosensitivity tests were performed. Chloroquine diphosphate (Sigma Chemicals) was tested as described elsewhere (Randrianarivelojosia et al., 2002). Isradipine (Icaz ${ }^{\circledR}$ LP, Laboratoires Sandoz, France) test
} 
concentrations ranged from 2 to $200 \mu \mathrm{M}$. The effect of isradipine on the activities of the antimalarials was determined by combination test (Martin et al., 1987). The chloroquine-resistant strain P. falciparum FCM29 maintained in continuous culture was also tested immediately after synchronization using the sorbitol-based method (Lambros \& Vanderberg, 1979).

2.5 and $6 \mu \mathrm{M}$ of isradipine were separately combined with chloroquine. Isobolograms were constructed by plotting a pair of fractional IC50s for each combination of isradipine and the antimalarial drugs. Antimalarial drug fractional IC50s were calculated by dividing the IC50 of the drug combined with isradipine by the IC50 of the drug alone, and these data were plotted on the horizontal axis. The corresponding isradipine fractional IC50 was calculated by dividing each fixed concentration by the IC50 of isradipine alone. These data were plotted on the vertical axis. Only combined isradipine concentrations less than isradipine IC50 (tested alone) were used in the final analysis. An isobologram close to the diagonal indicates an additive effect. Curves significantly above or below the diagonal indicate antagonistic or synergistic effects, respectively (Berenbaum, 1978; Martin et al., 1987).

\section{RESULTS AND DISCUSSION}

C50 values are reported in the table. Chloroquine plus isradipine was successfully tested on three fresh wild isolates of $P$. falciparum and also on $P$. falciparum FCM29 strain. In the three isolates, isobolograms shape indicated the antagonistic effect of isradipine on chloroquine antiplasmodial activity, while in FCM29 the isobologram almost indicates additive effects (Fig. 2; Table I).

Martiney et al. (1995) reported that in short time incubation, verapamil was found to increase chloroquine accumulation in erythrocytes infected with both chloroquine-sensitive and -resistant parasites, but only to affect the chloroquine susceptibility of the latter. Since

\begin{tabular}{rcc}
\hline & $\begin{array}{c}\text { Isradipine } \\
\text { IC50 in } \mathbf{~ M M}\end{array}$ & $\begin{array}{c}\text { Chloroquine } \\
\text { IC50 in } \mathbf{~ M M}\end{array}$ \\
\hline $\begin{array}{r}\text { P. falciparum } \\
\text { wild isolates }\end{array}$ & & \\
96065 & 11.4 & 33.9 \\
96067 & 12.9 & 51.1 \\
96068 & 15.3 & 64.5 \\
P. falciparum & $23.2 \pm 5.8^{\mathrm{c}}$ & $316 \pm 21.6^{\mathrm{c}}$ \\
FCM29 strain $^{\mathrm{b}}$ & & \\
\hline
\end{tabular}

a: tested once; b: tested three times; c: 2 standard deviation.

Table I. - In vitro response of three chloroquine-sensitive $P$. falciparum isolates and of chloroquine-resistant P. falciparum FCM29 strain to isradipine and chloroquine in vitro.

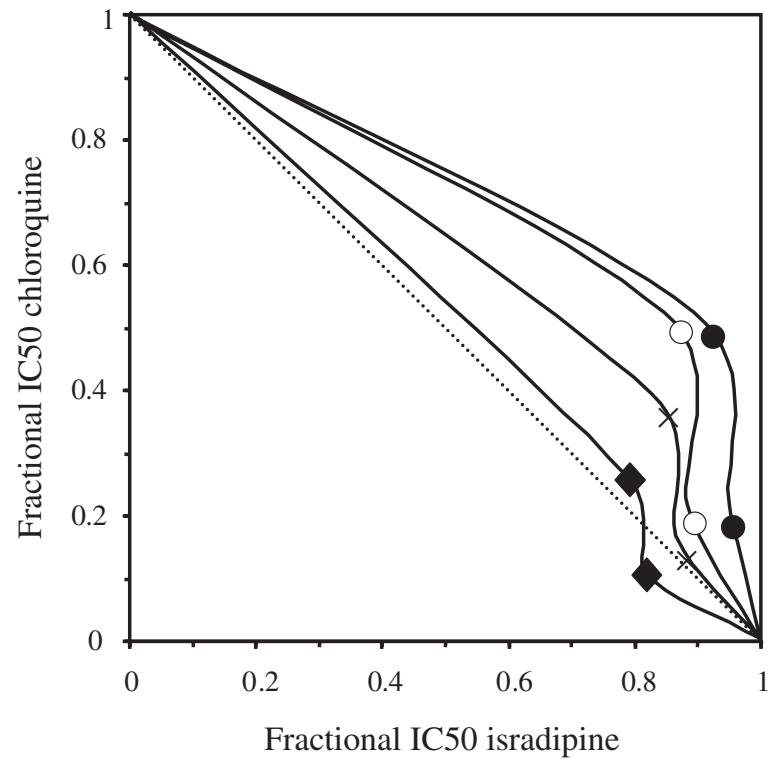

Fig. 2. - Isobolograms of in vitro drug interaction between isradipine and chloroquine against the chloroquine-resistant $P$. falciparum FCM29 strain $(\checkmark)$ and against three chloroquine-sensitive wild isolates of P. falciparum coded 96065 (×); 96067 (O) and $96068(\bullet$ from Madagascar.

tested isolates were chloroquine-sensitive (and did not harbour mutant pfcrt parasites, PCR/RFLP data not shown), it should not be surprising that isradipine does not potentiate chloroquine activity. But this does not explain the antagonism between isradipine and chloroquine.

Persson et al. (1989) reported that the mean plasma concentration of isradipine three hours after tablet intake was $3.14 \mathrm{ng} / \mathrm{ml}$ in 15 patients treated for essential hypertension. By comparison with this average therapeutic plasmatic concentration, the combined isradipine concentrations in our in vitro study were over 250 times higher. That makes questionable the relevance of these in vitro findings with regard to the possible in vivo drug interaction with chloroquine in a patient taking isradipine.

Thus, our preliminary results demonstrate that on the basis of isobologram, isradipine antagonises chloroquine antiplasmodial activity in wild chloroquine-sensitive $P$. falciparum, however only at very high concentrations. Even in chloroquine-resistant strain P. falciparum FCM29, isradipine does not potentiate chloroquine activity. Isradipine belongs to the dihydropyridine chemical family as does amlodipine, while verapamil is a phenylalkylamine. Still our results demonstrate that the calcium channel blocking properties are in no way correlated with systematic resistance reversal as already pointed out by Basco \& Le Bras (1991) when they showed that the reversal of chloroquine resistance by the enantiomers of amlodipine is independent of calcium metabolism of malaria parasites. The mechanism of resistance reversal 
by calcium channel blockers still remains unclear. But Mercereau-Puijalon \& Fandeur (2003) reported the intriguing possibility that both mefloquine and artemisinins could interfere with calcium homeostasis. A better understanding of the calcium homeostasis in malaria parasites would be an advance for malaria therapy.

\section{ACKNOWLEDGEMENTS}

e thank Dr Patrick Roig who provided us with isradipine. This study was supported by the French government via FSP projects.

\section{REFERENCES}

BASCO L.K. \& Le BRAS J. Plasmodium falciparum: in vitro drug interaction between chloroquine and enantiomers of amlodipine. Experimental Parasitology, 1999, 72, 262-270.

Berenbaum M.C. A method for testing for synergy with any number of agents. Journal of Infectious Diseases, 1978, 137, 122-130.

Kyle D.E., Oduola A.M., Martin S.K. \& Milhous W.K. Plasmodium falciparum: modulation by calcium antagonists of resistance to chloroquine, desethylchloroquine, quinine, and quinidine in vitro. Transactions of the Royal Society of Tropical Medicine and Hygiene, 1990, 84, 474-478.

LAmbros C. \& VANDERBERG J.P. Synchronization of Plasmodium falciparum erythrocytic stages in culture. J. Parasitology, 1979, 65, 418-420.

Martin S.K., Oduola A.M. \& Milhous W.K. Reversal of chloroquine resistance in Plasmodium falciparum by verapamil. Science, 1987, 235, 899-901.

Martiney J.A., Cerami A. \& Slater A.F. Verapamil reversal of chloroquine resistance in the malaria parasite Plasmodium falciparum is specific for resistant parasites and independent of the weak base effect. Journal of Biological Chemistry, 1995, 270, 22393-22398.

Mercereau-Puijalon O. \& Fandeur T. Antimalarial activity of artemisinins: identification of a novel target? Lancet, 2003, 362, 2035-2036.

Persson B., Andersson O.K., Wysocki M., Hedner T. \& Aurel M. Renal and hemodynamic effects of isradipine in essential hypertension. American Journal of Medicine, 1989, 86 (4A), 60-64.

Randrianarivelojosia M., Ratsimbasoa A., Randrianasolo L., RANDRIANARIJAONA A. \& JAMBOU R. In vitro sensitivity of Plasmodium falciparum to chloroquine, halofantrine, mefloquine and quinine in Madagascar. East African Medical Journal, 2002, 79, 237-241.

Scheibel L.W., Colombani P.M., Hess A.D., Aikawa M., AtkinsON C.T. \& Milhous W.K. Calcium and calmodulin antagonists inhibit human malaria parasites (Plasmodium falciparum): implications for drug design. Proceedings of the National Academy of Sciences USA, 1987, 84, 7310-7314.

Reçu le 24 janvier 2005

Accepté le 28 février 2005 